\title{
L'Église entre la loi et la règle
}

Auxerre, Centre d'études médiévales, 24 et 25 novembre 2011

Dominique logna-Prat et Alain Rauwel

\section{(2) OpenEdition}

Journals

Édition électronique

URL : https://journals.openedition.org/cem/12043

DOI : $10.4000 /$ cem. 12043

ISSN : 1954-3093

Éditeur

Centre d'études médiévales Saint-Germain d'Auxerre

Édition imprimée

Pagination : 381-382

ISSN : $1623-5770$

Référence électronique

Dominique logna-Prat et Alain Rauwel, «L'Église entre la loi et la règle », Bulletin du centre d'études médiévales d'Auxerre | BUCEMA [En ligne], 15 | 2011, mis en ligne le 24 août 2011, consulté le 22 septembre 2022. URL : http://journals.openedition.org/cem/12043 ; DOI : https://doi.org/10.4000/ cem. 12043

Ce document a été généré automatiquement le 22 septembre 2022.

\section{(c) $)(1)(2)$}

Creative Commons - Attribution - Pas d'Utilisation Commerciale - Partage dans les Mêmes Conditions 4.0 International - CC BY-NC-SA 4.0

https://creativecommons.org/licenses/by-nc-sa/4.0/ 


\title{
L'Église entre la loi et la règle
}

\author{
Auxerre, Centre d'études médiévales, 24 et 25 novembre 2011 \\ Dominique logna-Prat et Alain Rauwel
}

«Jésus annonçait le Royaume, et c'est l'Église qui est venue »: on connaît le mot célèbre de Loisy, à l'origine de l'une des grandes tempêtes doctrinales de la modernité L'Évangile et l'Église, 1902. Il dit bien le paradoxe de l'Ecclesia, dont la logique première serait d'être une communauté eschatologique, mais dont la nécessité, c'est-à-dire le retard de la Parousie, a fait une société réglée. La règle, en grec, se dit canon, et la somme des canons instaure un droit propre, tôt constitué tant était puissant en Occident le modèle des codifications impériales romaines. Le rôle de ce droit dans l'auto-conscience de l'Église latine est une évidence: à partir du moment où une institution définit légalement ses cadres et son fonctionnement, elle se pense à partir des catégories ainsi instituées. Le corpus canonique ne doit donc pas être lu uniquement comme un appareil normatif, dont le développement serait parallèle à celui des élaborations doctrinales. Non seulement les deux ensembles textuels sont sécants, mais encore ils expriment, en des «styles » différents, un discours unique sur une réalité unique : l'Église.

2 Pour autant, en Chrétienté, on distingue des phases d'intensité canonique inégale. L'apogée, qui vient immédiatement à l'esprit, est le temps de Gratien, lorsque l'Occident se dota d'une somme unifiée de références. Mais il y avait déjà eu, auparavant, des lieux et des moments de particulier engouement pour la législation ecclésiastique, avec la compilation de « collections canoniques », au rayonnement parfois spectaculaire. Le cas de l'Espagne, de ce point de vue, est emblématique. Il n'est pas indifférent que la patrie de l'Hispana, la plus diffusée des collections, soit aussi le terrain d'élaboration d'un modèle ecclésial puissamment original, dont des rites propres manifestaient la singularité. Le croisement de ces deux réalités, qui est au cœur des travaux de Thomas Deswarte, mérite à coup sûr d'être examiné à nouveaux frais.

3 Canon sive regula: sans doute. Mais « règle », outre son sens générique, désigne aussi ces textes très particuliers qui régissent de petites Églises dans la grande: les communautés monastiques, ces lieux où l'on ne se contente pas d'être chrétien comme tout le monde, par la seule grâce du baptême, mais où le vœu manifeste une 
"conversion seconde» (Alain Boureau), instauratrice d'une aspiration à l'excellence spirituelle. Des interprétations très diverses de la régularité y ont cohabité. À côté des «rappels à la règle», qui ont ponctué les innombrables ambitions de réformer le monachisme et dont témoignerait le genre des commentaires sur saint Benoît, de Smaragde à Rupert de Deutz (et bien au-delà), ont fleuri des lectures plus ambitieuses, plus déstabilisatrices parfois. Sur ce plan comme sur bien d'autres, les cisterciens sont en première ligne. La réhabilitation de l'affect dont ils sont à la fois, au XII siècle, les artisans et les chantres (Damien Boquet), les conduit à envisager un cloître schola caritatis régi par la vertu d'amitié, héritée du cicéronianisme: que devient alors le principe régulier et quel sens y a-t-il à parler d'une ecclésiologie de l'amitié? Les choses se compliquent encore si l'on prend la mesure de la question nouvelle posée, au même siècle, par le « désir monastique » des femmes. Les hésitations des plus grands, à commencer par saint Bernard, disent bien comment les communautés féminines, étudiées par Alexis Grelois, sont un coin introduit dans le bel agencement du bloc clérical masculin, forcément masculin. Elles obligent à penser une Église diversifiée, complexifiée.

Diversification et complexification sont aussi deux mots-clefs pour la période de la première modernité, entre $\mathrm{xv}^{\mathrm{e}}$ et $\mathrm{XvII}^{\mathrm{e}}$ siècle. L'Église a traversé la crise du conciliarisme, elle fait face à des contestations d'un type nouveau, elle doit se redéfinir - Trente, certes, mais déjà Latran $\mathrm{V}$, ce concile méconnu. En canonistique, c'est l'âge post-classique, dont Patrick Arabeyre montre les rapports étroits avec les débats politiques et ecclésiaux des années 1500. Des voix nouvelles, par exemple celle des parlements, se font entendre dans le concert ecclésiologique, qui en prend parfois des allures de cacophonie. Un groupe nouveau, celui des érudits, adapte les techniques de la philologie humaniste aux vieilles pratiques d'instrumentalisation de l'histoire ecclésiastique, notamment de son histoire canonique, au service des combats du jour. $\mathrm{Au}$ final, malgré tout, l'harmonie qui s'instaure est plutôt un succès.

5 Mais est-elle si radicalement neuve ? En dépit de toutes les avancées récentes, il reste encore un peu provocateur, dans le paysage académique de 2011, de militer pour une étude du phénomène ecclésial sur la très longue durée du régime de Chrétienté, au-delà de la sacro-sainte rupture entre "Moyen Âge» et «temps modernes». Les faits, pourtant, sont têtus : l'Église tridentine ne se comprend pas sans l'Église grégorienne, dont elle n'est peut-être, en somme, que la brillante réactualisation. L'inlassable discours de ceux qui ont pensé l'institution, le vivre-ensemble de tous les chrétiens comme le vivre-ensemble des chrétiens quintessenciés des monastères et des couvents, est un bon observatoire pour mesurer la continuité, pour mesurer la nouveauté. La rencontre d'Auxerre voudrait être, aussi, un plaidoyer pour un nouveau décloisonnement des études religieuses.

6 Participants : P. Arabeyre, E. Coccia, T. Deswarte, R. Eckert, F. Gabriel, A. Grélois, P. Henriet, D. Iogna-Prat, B. Marceau, A. Rauwel... 
INDEX

Mots-clés : église, loi, règle 